\title{
Characterization of quinolone-resistant Enterobacteriaceae strains isolated from poultry in Western Algeria: First report of qnrS in an Enterobacter cloacae
}

\author{
Qada Benameur ${ }^{1,2}$, Hassiba Tali-Maamar ${ }^{3}$, Farida Assaous ${ }^{3}$, Badia Guettou³, Meki Boutaiba Benklaouz ${ }^{4}$, Kheira Rahal ${ }^{3}$ and \\ Meriem-Hind Ben-Mahdi ${ }^{2,5}$ \\ 1. Faculty of Natural Sciences and Life, Abdelhamid Ibn Badis University, Mostaganem, Algeria; 2. Research Laboratory, \\ Health and Animal Production, Higher National Veterinary School, Algiers, Algeria; 3. Medical Bacteriology Laboratory, \\ Pasteur Institute of Algeria, Algiers, Algeria; 4. Veterinary Sciences Institute, Ibn Khaldoun University, Tiaret, Algeria; \\ 5. Higher School of Food Sciences and Agro-alimentary Industries, Algiers, Algeria. \\ Corresponding author: Qada Benameur, e-mail: qada.benameur@univ-mosta.dz \\ Co-authors: HT: htali@yahoo.fr, FA: fassaous@yahoo.fr, BG: beachedz@yahoo.fr, MBB: meki1327@yahoo.com, \\ KR: kheirarahal@gmail.com, MHB: mhbenmahdi.ensv@gmail.com \\ Received: 21-12-2017, Accepted: 06-03-2018, Published online: 12-04-2018
}

doi: 10.14202/vetworld.2018.469-473 How to cite this article: Benameur Q, Tali-Maamar H, Assaous F, Guettou B, Boutaiba Benklaouz M, Rahal K, Ben-Mahdi MH (2018) Characterization of quinolone-resistant Enterobacteriaceae strains isolated from poultry in Western Algeria: First report of qnrS in an Enterobacter cloacae, Veterinary World, 11(4): 469-473.

\begin{abstract}
Aim: Multidrug-resistant (MDR) Enterobacteriaceae have frequently been reported, in both human and veterinary medicine, from different parts of the world as a consequence of antibiotic usage. However, there is a lack of published data regarding antimicrobial resistance in non-Escherichia coli (E. coli) Enterobacteriaceae from animals in Algeria. This study aimed to evaluate the frequency of resistance to antibiotics with a focus on quinolones and to investigate the presence of qnr genes in Enterobacteriaceae of poultry origin.

Materials and Methods: A total of 310 samples of poultry origin were collected from 2010 to 2014 from broiler and layer farms and hatcheries located in different geographic areas of Western Algeria (including Mostaganem, Oran, Mascara, Relizane, Chlef, Tiaret, and Tissemsilt). Antimicrobial susceptibility testing was performed using disc diffusion assay. Polymerase chain reaction and sequencing accomplished the characterization of qnr genes (qnrA, qnrB, and qnrS).
\end{abstract}

Results: A total of 253 Enterobacteriaceae strains were isolated in this study. These isolates exhibited high levels of resistance to quinolones and other families of antibiotics. All the strains isolated in this study were resistant to at least one antibiotic. Among them, 233 (92.09\%) were considered MDR. Among the 18 randomly selected nalidixic acid (NA)resistant Enterobacteriaceae isolates, one E. coli and one Enterobacter cloacae were carrying qnrS1. By contrast, qnrA and $q n r B$ were not detected in this study.

Conclusion: This is the first report on the identification of the $q n r S$ gene in E. cloacae isolated from animal source in Algeria. Further studies have to be conducted to determine the real prevalence of qnr genes.

Keywords: Algeria, antimicrobial resistance, Enterobacteriaceae, qnrS1.

\section{Introduction}

Quinolones and fluoroquinolones are broad-spectrum antimicrobial agents, extensively used in poultry disease treatment. This widespread use has been associated worldwide with an increased level of resistance, especially in Gram-negative bacteria species in the last decade [1,2]. Multidrug-resistant (MDR) Enterobacteriaceae have frequently been reported, in both human and veterinary medicine, from different parts of the world as a consequence of antibiotic usage $[3,4]$. In Algeria, the frequency of antimicrobial resistance in Escherichia coli (E. coli) from animals has already been reported by several authors [5-8].

Copyright: Benameur, et al. Open Access. This article is distributed under the terms of the Creative Commons Attribution 4.0 International License (http://creativecommons.org/licenses/ by/4.0/), which permits unrestricted use, distribution, and reproduction in any medium, provided you give appropriate credit to the original author(s) and the source, provide a link to the Creative Commons license, and indicate if changes were made. The Creative Commons Public Domain Dedication waiver (http:// creativecommons.org/publicdomain/zero/1.0/) applies to the data made available in this article, unless otherwise stated.
However, there is a lack of published data regarding antimicrobial resistance in non-E. coli Enterobacteriaceae from animals in Algeria. It is admitted that resistance to quinolones results from both chromosomal and plasmid-mediated quinolone resistance (PMQR) mechanisms. Qnr genes represent one of the most important PMQR mechanisms. These genes encode pentapeptide repeat proteins that block the action of ciprofloxacin (CIP) on bacterial DNA gyrase and topoisomerase IV $[9,10]$. Three major groups of Qnr determinants have been described (QnrA, QnrB, and QnrS), which share between $40 \%$ and $60 \%$ similarity [11]. These determinants have been identified worldwide in various Enterobacteriaceae, and they have frequently been associated with extended-spectrum $\beta$-lactamases (ESBLs) and plasmidic cephalosporinases [12,13].

In Algeria, these determinants have been reported in various human Enterobacteriaceae [14-16]. However, the occurrence of these resistance determinants in isolates of animal origin in Algeria is rarely documented. 
This study aimed to evaluate the frequency of resistance to quinolones and other groups of antibiotics in Enterobacteriaceae isolated from poultry in Western Algeria and to investigate the presence of $q n r$ genes in a collection of nalidixic acid (NA)-resistant Enterobacteriaceae isolates.

\section{Materials and Methods}

\section{Ethical approval}

Ethical approval is not needed to pursue this type of study. However, no chickens were harmed during the collection of samples.

\section{Bacterial strains}

From December 2010 to January 2014, 253 non-duplicate Enterobacteriaceae strains were isolated from 310 samples received in the Regional Veterinary Laboratory of Mostaganem, Algeria, for routinely control of Salmonella. All samples were collected by veterinarians controlling from farms and hatcheries located in different geographic areas of Western Algeria (including Mostaganem, Oran, Mascara, Relizane, Chlef, Tiaret, and Tissemsilt). The samples nature received were healthy and diseased broiler and layer breeders, 1 day-old broiler and layer chicks, broilers, laying hens, and farm swabs. The isolates were recovered from internal organs (liver, spleen, or pericardium), fecal samples, or farm swabs. For the primary isolation, one $\mathrm{mL}$ of sample was inoculated with nine $\mathrm{mL}$ of buffered peptone water vortexed and incubated at $37^{\circ} \mathrm{C}$ overnight. Then, a drop of broth was streaked on MacConkey agar and incubated at $37^{\circ} \mathrm{C}$ overnight. The Enterobacteriaceae isolates were identified biochemically by classical biochemical testing or using the API 20E system (bioMérieux, Marcy l'Étoile, France).

\section{Antimicrobial susceptibility testing}

The antimicrobial susceptibility of all isolated Enterobacteriaceae strains was tested following Clinical and Laboratory Standards Institute (CLSI) guidelines [17]. The isolates were tested against a panel of 12 antimicrobials: Nalidixic acid (NA, $30 \mu \mathrm{g}$ ), flumequin (UB, $30 \mu \mathrm{g}$ ), ciprofloxacin (CIP, $5 \mu \mathrm{g}$ ), ampicillin (AM, $10 \mu \mathrm{g}$ ), amoxicillin/clavulanic acid (AMC, 20/10 $\mu \mathrm{g}$ ), ceftiofur (XNL, $30 \mu \mathrm{g}$ ), tetracycline (TE, $30 \mu \mathrm{g}$ ), trimethoprim/sulfamethoxazole (SXT, 1.25/23.75 $\mu \mathrm{g})$, neomycin $(\mathrm{N}, 30 \mu \mathrm{g})$, gentamicin $(\mathrm{CN}, 15 \mu \mathrm{g})$, chloramphenicol $(\mathrm{C}, 30 \mu \mathrm{g})$, and colistin $(\mathrm{CT}, 50 \mu \mathrm{g})$ (Bio-Rad, Marnes la Coquette, France). Results were obtained after incubating samples for $16-18 \mathrm{~h}$ at $37^{\circ} \mathrm{C}$ and were interpreted according to CLSI previously cited guidelines. E. coli ATCC 25922 was used as a quality control strain.

Polymerase chain reaction (PCR) and DNA sequencing

A total of $18 \mathrm{MDR}$ isolates randomly selected among NA-resistant Enterobacteriaceae isolates werescreened by multiplex PCR amplification of $q n r A$, $q n r B$, and $q n r S$ as previously described [18-20], after extraction of total DNA by the boiling method. Primers used were as follows: for $q n r A, 5$ '-TTCTCACGCCAGGATTTGAG and 5'-TGCCAGGCACAGATCTTGAC, to give a 571 pb product; for $q n r B, 5$ '-TGGCGAAAAATT(GA) ACAGAA and 5'-GAGCAACAG(TC) GCCTGGTAG, to give a $594 \mathrm{pb}$ product; and for $q n r S, \quad 5$ '-GACGTGCTAACTTGCGTGAT and 5'-GACGTGCTAACTTGCGTGAT, to give a $388 \mathrm{pb}$ product. All the six primers were added to the template DNA and PCR mix (Invitrogen, Carlsbad, CA). The following cycle conditions were used: Initial denaturation at $95^{\circ} \mathrm{C}$ for $5 \mathrm{~min}$, followed by 30 cycles of denaturation at $94^{\circ} \mathrm{C}$ for $1 \mathrm{~min}$, annealing at $60^{\circ} \mathrm{C}$ for $45 \mathrm{~s}$ and amplification at $72^{\circ} \mathrm{C}$ for $1 \mathrm{~min}$, and a final extension at $72^{\circ} \mathrm{C}$ for $10 \mathrm{~min}$. Negative controls (without DNA template) were included in each run. Amplification products were provisionally identified from their sizes in agarose gels. Amplification products were separated by electrophoresis, on $1.5 \%$ ethidium bromide-stained agarose gels in $1 \times$ TBE buffer at $150 \mathrm{~V}$ for $1 \mathrm{~h}$, and then visualized under ultraviolet light. PCR amplicons were confirmed by sequencing and the DNA sequences obtained were compared with those in the GenBank using the BLAST program (http://www.ncbi.nlm.nih.gov/BLAST).

\section{Results and Discussion}

\section{Antimicrobial susceptibility of Enterobacteriaceae isolates}

Two hundred and fifty three Enterobacteriaceae strains were isolated from 310 poultry samples received in the Regional Veterinary Laboratory of Mostaganem, Northwestern Algeria. The isolates consisted of 134 E. coli, 55 Enterobacter cloacae (E. cloacae), 42 Klebsiella pneumoniae (K. pneumoniae), 10 Proteus mirabilis, 7 Serratia marcescens, and 5 Providencia rettgeri. The percentage of antimicrobial resistance of the predominant Enterobacteriaceae strains isolated in this study is shown in the Figure-1. E. coli isolates showed a high resistance rate to particular antimicrobials, notably TE $94.77 \%(n=127)$, NA $94.03 \%(n=126), A M$ 94.03\% ( $\mathrm{n}=126)$, UB 93.28\% $(\mathrm{n}=125)$, CIP $85.10 \%$ $(\mathrm{n}=114)$, and SXT 76.11\% $(\mathrm{n}=102)$. Among E. cloacae isolates, the highest proportion of resistance was toward AM $90.90 \%(n=50)$, followed by NA $83.63 \%$ $(\mathrm{n}=46)$, UB 76.36\% $(\mathrm{n}=42)$, TE $74.54 \%(\mathrm{n}=41)$, CIP $65.45 \%(\mathrm{n}=36)$, and SXT $52.72 \%(\mathrm{n}=29)$. Resistance of $K$. pneumoniae to AM, NA, UB, CIP, TE, SXT, and AMC was, respectively, observed in $100 \%(\mathrm{n}=42)$, $92.85 \% \quad(n=39), 92.85 \% \quad(n=39), 90.47 \% \quad(n=38)$, $85.71 \%(\mathrm{n}=36), 57.14 \%(\mathrm{n}=24)$, and $57.14 \%(\mathrm{n}=24)$ of the isolates. All the isolates examined in this study were resistant to at least one antibiotic. Among them, $233(92.09 \%)$ were considered MDR (resistant to three or more different antimicrobial agents belonging to different classes of antibiotics) (Table-1). K. pneumoniae and $E$. coli are the most common opportunistic Enterobacteriaceae, and their growing cross-resistance 
to quinolones is a critical problem [21,22]. In Algeria, there is a lack of published data regarding antimicrobial resistance in non-E. coli and non-Salmonella spp. Enterobacteriaceae of animal origin. Resistance of $E$. coli isolates to quinolones was far higher compared to previous studies conducted in Algeria [6,7]. In view of the whole range of antibiotics available in Algeria and the increasing and inappropriate use of quinolones in poultry farms, the globally high incidence of antibiotic resistance observed in this study is not really surprising.

\section{Qnr occurrence}

The $q n r$ multiplex PCR allowed the detection of two positive isolates (one E. coli and one E. cloacae), both of them were carrying qnrS1 (Table-2), whereas $q n r A$ and $q n r B$ were not identified in any of the 18 randomly selected isolates. In Algeria, several studies allowed the detection of $q n r$ determinants in human clinical isolates [12-14]. However, few studies reported their presence in isolates of animal origin. $q n r A$ has been recently identified in ESBL producing $E$. coli isolates from poultry [23], and qnrS1 and qnrB5 in ESBL producing $E$. coli isolates from companion animals [24]. To the best of our knowledge, this is the first description of qnrS genes in an E. cloacae isolate from animal source in Algeria. All of the previously cited Algerian studies detected the presence of $q n r$ determinants in ESBL producing isolates. However, no study reported their presence in non-ESBL Enterobacteriaceae in our country. The qnrS gene has been previously detected in several Salmonella strains isolated from poultry source in Denmark, Germany, and Netherland [25-27] and was also reported in E. coli isolates from food-producing animals in China and Nigeria [28,29]. Typically, $q n r B$ was considered to be the most prevalent PMQR gene in Enterobacteriaceae isolates [11]. The other 16 NA -resistant Enterobacteriaceae isolates tested in this study were negative for the three qnr genes investigated. However, they were not tested for other $q n r$ determinants ( $q n r C$, $q n r D$, and $q n r V C)$. Thus, this preliminary study have to be completed by further investigations of other PMQR determinants, including $q n r C$, qnrD, qnrVC, aac(6')-Ib-cr, qepA, and oqxAB. $q n r$ genes have been either detected alone or in association with ESBL genes in a range of bacterial species [30]. Recently, qnrA or qnrS determinants were identified in non-ESBL-positive isolates harboring TEM-1 or $L A P-1$ [31]. As previously reported, our results confirmed that the spread of these genes can be independent and not always associated with $b l a_{\mathrm{ESBL}}$ genes $[2,31]$.

E. coli harboring qnrS1 gene, detected in our study, was resistant to CIP, whereas the qnrSl positive E. cloacae were susceptible to CIP. Quinolone resistance has been described to be transmitted by plasmids carrying $q n r$ genes [32], resulting in low-level quinolone resistance and it can facilitate the selection of quinolone-resistant mutants with higher-level resistance [33,34]. The transferability of CIP -resistant E. coli or mobile resistance determinants from chickens to humans has been indicated in several studies $[35,36]$. Since the zoonotic transfer of fluoroquinolone-resistant bacteria is of concern from a human health perspective, the reverse scenario - the transfer of fluoroquinolone-resistant bacteria from humans to animals - warrants equal consideration, which may be responsible for therapeutic failures in animals.

\section{Conclusions}

This study revealed high levels of antimicrobial resistance to antibiotics with a focus on quinolones in Enterobacteriaceae isolates. This is the first detection of $q n r S$ in E. cloacae isolates from the animal in Algeria. The emergence of PMQR thus may contribute by several means to the rapid and deleterious increase in bacterial resistance to fluoroquinolones. These fluoroquinolone-resistant bacteria may be transferred from animals to humans and vice versa, increasing the risk of treatment failure. Therefore, implementation of more efficient preventive measures at all levels of broiler and layer industries is becoming mandatory.

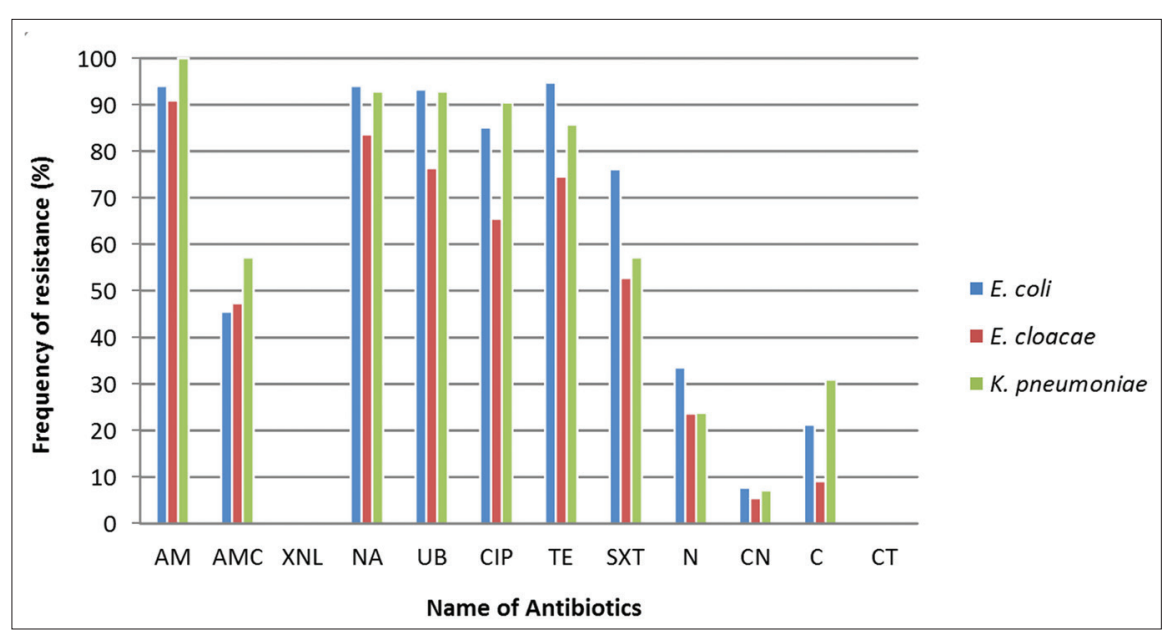

Figure-1: Antimicrobial resistance among Enterobacteriaceae. AM=Ampicillin, AMC=Amoxicillin/clavulanic acid, $X N L=$ Ceftiofur, $\quad N A=$ Nalidixic acid, UB=Flumequin, CIP=Ciprofloxacin, TE=Tetracycline, SXT=Trimethoprim/ sulfamethoxazole, $\mathrm{N}=$ Neomycin, $\mathrm{CN}=$ Gentamicin, $\mathrm{C}=$ Chloramphenicol, $\mathrm{CT}=$ Colistin. 
Table-1: MDR in Enterobacteriaceae isolates.

\begin{tabular}{lcc}
\hline Organism & Total No. & $\begin{array}{c}\text { Number of MDR } \\
\text { isolates (\%) }\end{array}$ \\
\hline E. coli & 134 & $125(93.28)$ \\
E. cloacae & 55 & $52(94.54)$ \\
K. pneumoniae & 42 & $39(92.85)$ \\
P. mirabilis & 10 & $8(80.00)$ \\
S. marcescens & 7 & $5(71.42)$ \\
P. rettgeri & 5 & $4(80.00)$ \\
Total & 253 & $233(92.09)$ \\
\hline
\end{tabular}

MDR=Multidrug resistant, $E$. coli=Escherichia coli,

E. cloacae $=$ Enterobacter cloacae,

K. pneumoniae $=$ Klebsiella pneumoniae,

P. mirabilis $=$ Proteus mirabilis,

S. marcescens=Serratia marcescens,

P. rettgeri=Providencia rettgeri

Table-2: Enterobacteriaceae isolates tested by PCR for the determination of $q n r$ determinants.

\begin{tabular}{|c|c|c|}
\hline Strain & qnr & $\begin{array}{l}\text { Antimicrobial } \\
\text { resistance pattern }\end{array}$ \\
\hline E. coli (S1) & l & NA, UB, CIP, AM, SXT \\
\hline E. coli (S2) & / & NAL, UB, CIP, AM, TE \\
\hline E. coli (S3) & / & $\begin{array}{l}\text { NAL, UB, CIP, AM, } \\
\text { SXT, TE }\end{array}$ \\
\hline E. coli (S4) & l & NAL, UB, CIP, AM, TE \\
\hline E. coli (S5) & / & NAL, UB, CIP \\
\hline E. coli (S6) & qnrS1 & $\begin{array}{l}\text { NAL, UB, CIP, AM, } \\
\text { SXT, TE }\end{array}$ \\
\hline E. coli (S7) & / & $\begin{array}{l}\text { NAL, UB, CIP, AM, } \\
\text { SXT, TE, N }\end{array}$ \\
\hline E. coli (S8) & / & $\begin{array}{l}\text { NAL, UB, CIP, AM, } \\
\text { SXT, TE }\end{array}$ \\
\hline P. rettgeri (S9) & / & $\begin{array}{l}\text { NAL, UB, CIP, AM, } \\
\text { AMC, SXT, TE, CN, C }\end{array}$ \\
\hline E. coli (S10) & / & NAL, UB, SXT, TE \\
\hline K. pneumoniae (S11) & / & $\begin{array}{l}\text { NAL, UB, CIP, AM, } \\
\text { SXT, TE, C }\end{array}$ \\
\hline E. cloacae (S12) & qnrS1 & $\begin{array}{l}\text { NAL, UB, AM, AMC, } \\
\text { TE, SXT }\end{array}$ \\
\hline E. coli (S13) & / & $\begin{array}{l}\text { NAL, UB, AM, AMC, } \\
\text { SXT, TE }\end{array}$ \\
\hline E. coli (S14) & / & $\begin{array}{l}\text { NAL, UB, AM, AMC, } \\
\text { SXT, TE }\end{array}$ \\
\hline E. coli (S15) & / & $\begin{array}{l}\text { NAL, UB, CIP, AM, } \\
\text { SXT, TE, N }\end{array}$ \\
\hline E. coli (S16) & / & $\begin{array}{l}\text { NAL, UB, CIP, AM, } \\
\text { SXT, TE }\end{array}$ \\
\hline E. coli (S17) & / & $\begin{array}{l}\text { NAL, UB, CIP, AM, } \\
\text { SXT, TE, N }\end{array}$ \\
\hline E. coli (S18) & / & $\begin{array}{l}\text { NAL, UB, CIP, AM, } \\
\text { SXT, TE, CN }\end{array}$ \\
\hline
\end{tabular}

$\mathrm{NA}=$ Nalidixic acid $\mathrm{UB}=$ flumequine $\mathrm{CIP}=$ Ciprofloxacin; $\mathrm{AM}=$ Ampicillin; $\mathrm{AMC}=$ Amoxicillin/clavulanic acid;

SXT=Trimethoprim/sulfamethoxazole; TE=Tetracycline; $\mathrm{N}=$ Neomycin; $\mathrm{CN}=$ Gentamicin; $\mathrm{C}=$ Chloramphenicol, E. coli=Escherichia coli, E. cloacae=Enterobacter cloacae,

K. pneumoniae $=$ Klebsiella pneumoniae,

$P$. rettgeri=Providencia rettgeri

\section{Authors' Contributions}

$\mathrm{QB}, \mathrm{FA}, \mathrm{BG}$, and $\mathrm{MBB}$ carried out the main research works and analyzed the main data in the experiments. HT, KR, and MHB have supervised the laboratory work and approved the final version of the manuscript. All authors read and approved the final manuscript.

\section{Acknowledgments}

The authors appreciate the staff of the veterinary practitioners for providing samples. A special thanks to Dr. Ben-Mahdi Tarek, the ex-Director of the Regional Veterinary Laboratory of Mostaganem, Algeria, Dr. Benbernou Sennia, Dr. Sebai Ali, Dr. Bouziri Abduldjalal, and Ms. Benkhamkham Naziha, for their skilled assistance in the laboratory work. This study was supported by internal funding.

\section{Competing Interests}

The authors declare that they have no competing interests.

\section{References}

1. Richter, S.N., Frasson, I., Bergo, C., Manganelli, R., Cavallaro, A. and Palu, G. (2010) Characterisation of $q n r$ plasmid-mediated quinolone resistance in Enterobacteriaceae from Italy: Association of the qnrB19 allele with the integron element ISCR1 in Escherichia coli. Int. J. Antimicrob. Agents., 35: 578-583.

2. Robicsek, A., Jacoby, G.A. and Hooper, D.C. (2006) The worldwide emergence of plasmid-mediated quinolone resistance. Lancet Infect. Dis., 6: 629-640.

3. Yadav, K.K., Adhikari, N., Khadka, R., Pant, A.D. and Shah, B. (2015) Multidrug-resistant Enterobacteriaceae and extended spectrum $\beta$-lactamase producing Escherichia coli: A cross-sectional study in national kidney center, Nepal. Antimicrob. Resist. Infect. Control., 4: 42.

4. Kilonzo-Nthenge, A., Rotich, E. and Nahashon, S.N. (2013) Evaluation of drug-resistant Enterobacteriaceae in retail poultry and beef. Poult. Sci., 92: 1098-1107.

5. Benameur, Q., Guemour, D., Hammoudi, A., Aoudia, K., Aggad, H., Humblet, M.H. and Saegermang, C. (2014) Antimicrobial resistance of Escherichia coli isolated from chickens in West of Algeria. Int. J. Sci. Basic Appl. Res., 13: 366-370.

6. Hammoudi, A. and Aggad, H. (2008) Antibioresistance of Escherichia coli strains isolated from chicken colibacillosis in Western Algeria. Turk. J. Vet. Anim. Sci., 32: 123-126.

7. Aggad, H., Ammar, Y.A., Hammoudi, A. and Kihal, M. (2010), Antimicrobial resistance of Escherichia coli isolated from chickens with colibacillosis. Glob. Vet., 4: 303-306.

8. Benameur, Q., Ben-Mahdi, M.H., Boutaiba Benklaouz, M., Tali-Maamar, H., Assaous, F., Guettou, B. and Rahal, K. (2016) Analysis of high levels of multidrug-resistant Escherichia coli from healthy broiler chickens in Western Algeria. Afr. J. Microbiol. Res., 10: 1792-1797.

9. Tran, J.H. and Jacoby, G.A. (2002) Mechanism of plasmid-mediated quinolone resistance. Proc. Natl. Acad. Sci. USA, 99: 5638-5642.

10. Tran, J.H., Jacoby, G.A. and Hooper, D.C. (2005) Interaction of the plasmid-encoded quinolone resistance protein QnrA with Escherichia coli topoisomerase IV. Antimicrob. Agents. Chemother., 49: 3050-3052.

11. Strahilevitz, J., Jacoby, G.A., Hooper, D.C. and Robicsek, A. (2009) Plasmid-mediated quinolone resistance: A multifaceted threat. Clin. Microbiol. Rev., 22: 664-689.

12. Cattoir, V., Poirel, L. and Nordmann, P. (2007) Plasmidmediated quinolone resistance determinant QnrB4 identified in France in an Enterobacter cloacae clinical isolate coexpressing a QnrS1 determinant. Antimicrob. Agents. Chemother., 51: 2652-2653.

13. Cambau, E., Lascols, C., Sougakoff, V., Bébéar, C., Bonnet, R., Cavallo, J.D., Gutmann, L., Ploy, M.C., Jarlier, V., Soussy, C.J. and Robert, J. (2006) Occurrence of qnrA-positive clinical isolates in French teaching hospitals during 2002-2005. Clin. Microbiol. Infect., 12: 1013-1020. 
14. Iabadene, H., Messai, Y., Ammari, H., Ramdani-Bouguessa, N., Lounes, S., Bakour, R. and Arlet, G. (2008) Dissemination of ESBL and Qnr determinants in Enterobacter cloacae in Algeria. J. Antimicrob. Chemother., 62: 133-136.

15. Meradi, L., Djahoudi, A., Abdi, A., Bouchakour, M., Claude, J.D. and Timinouni, M. (2011) Qnr and Aac(6')Ib-cr types quinolone resistance among Enterobacteriaceae isolated in Annaba, Algeria. Pathol. Biol., 59: 73-78.

16. Gharout-Sait, A., Touati, A., Benallaoua, S., Guillard, T., Brasm, T.J. and de Champs, C. (2012) CTX-M from community acquired urinary tract infections in Algeria. Afr. $J$. Microbiol. Res., 6: 5306-5313.

17. Clinical and Laboratory Standards Institute. (2015) Performance Standards for Antimicrobial Susceptibility Testing: Twenty-fifth Informational Supplement document M100S25. Wayne, PA: Clinical and Laboratory Standards Institute.

18. Jacoby, G.A., Chow, N. and Waites, K.B. (2003), Prevalence of plasmid-mediated quinolone resistance. Antimicrob. Agents. Chemother., 47: 559-562.

19. Jacoby, G.A., Walsh, K.E., Mills, D.M., Walker, V.J., Oh, H., Robicsek, A. and Hooper, D.C. (2006) qnrB, another plasmid-mediated gene for quinolone resistance. Antimicrob. Agents. Chemother., 50: 1178-1182.

20. Gay, K., Robicsek, A., Strahilevitz, J., Park, C.H., Jacoby, G., Barrett, T.J., Medalla, F., Chiller, T.M. and Hooper, D.C. (2006) Plasmid-mediated quinolone resistance in non-typhi serotypes of Salmonella enterica. Clin. Infect. Dis., 43: 297-304.

21. Ling, T.X., Xiong, J., Yu, Y., Lee, C.C., Ye, H. and Hawkey, P.M. (2006) Multicenter antimicrobial susceptibility survey of gram-negative bacteria isolated from patients with community-acquired infections in the people's republic of China. Antimicrob. Agents. Chemother., 50: 374-378.

22. Silva-Sanchez, J., Barrios, H., Reyna-Flores, F., BelloDiaz, M., Sanchez-Perez, A., Rojas, T., Bacterial Resistance Consortium and Garza-Ramos, U. (2011) Prevalence and characterization of plasmid-mediated quinolone resistance genes in extended-spectrum $\beta$-lactamase-producing Enterobacteriaceae isolates in Mexico. Microb. Drug. Resist., 17: 497-505.

23. Belmahdi, M., Bakour, S., Al Bayssari, C., Touati, A. and Rolain, J.M. (2016) Molecular characterization of extended-spectrum $\beta$-lactamase- and plasmid AmpC-producing Escherichia coli strains isolated from broilers in Béjaïa, Algeria. J. Glob. Antimicrob. Resist., 6: 108-112.

24. Yousfi, M., Mairi, A., Touati, A., Hassissene, L., Brasme, L., Guillard, T. and De Champs, C. (2016) Extended spectrum $\beta$-lactamase and plasmid-mediated quinolone resistance in Escherichia coli fecal isolates from healthy companion animals in Algeria. J. Infect. Chemother., 22: 431-435.

25. Cavaco, L.M., Hendriksen, R.S. and Aarestrup, F.M.
(2007) Plasmid-mediated quinolone resistance determinant qnrSl detected in Salmonella enterica serovar Corvallis strains isolated in Denmark and Thailand. J. Antimicrob. Chemother., 60: 704-706.

26. Ferrari, R., Galiana, A., Cremades, R., Rodriguez, J.C., Magnani, M., Tognim, M.C.B., Oliveira, T.C.R.M. and Royo, G. (2011) Plasmid-mediated quinolone resistance by genes qnrA1 and qnrB19 in Salmonella strains isolated in Brazil. J. infect. Dev. Ctries, 5: 496-498.

27. Veldman, K., van Pelt, W. and Mevius, D. (2008) First report of $q \mathrm{nr}$ genes in Salmonella in the Netherlands. $J$. Antimicrob. Chemother., 61: 452-453.

28. Fortini, D., Fashae, K., Garcia-Fernandez, A., Villa, L. and Carattoli, A. (2011) Plasmid-mediated quinolone resistance and beta-lactamases in Escherichia coli from healthy animals from Nigeria. J. Antimicrob. Chemother., 66: 1269-1272.

29. Ma, J., Zeng, Z., Chen, Z., Xu, X., Wang, X., Deng, Y., Lue, D., Huang, L., Zhang, Y., Liu, L. and Wang, M. (2009) High prevalence of plasmid-mediated quinolone resistance determinants $q n r, a a c\left(6^{\prime}\right)-I b-c r$, and qepA among ceftiofur-resistant Enterobacteriaceae isolates from companion and food-producing animals. Antimicrob. Agents. Chemother., 53: 519-524.

30. Kirchner, M., Wearing, H. and Teale, C. (2011) Plasmidmediated quinolone resistance gene detected in Escherichia coli from cattle. Vet. Microbiol., 148: 434-435.

31. Poirel, L., Leviandier, C. and Nordmann, P. (2006) Prevalence and genetic analysis of plasmid-mediated quinolone resistance determinants QnrA and QnrS in Enterobacteriaceae isolates from a French university hospital. Antimicrob. Agents. Chemother., 50: 3992-3997.

32. Robicsek, A., Strahilevitz, J., Sahm, D.F., Jacoby, G.A. and Hooper, D.C. (2006) Qnr prevalence in ceftazidime-resistant Enterobacteriaceae isolates from the United States. Antimicrob. Agents. Chemother., 50: 2872-2874.

33. Martinez-Martinez, L., Cano, M.E., RodriguezMartinez, J.M., Calvo, J. and Pascual, A. (2008) Plasmidmediated quinolone resistance. Expert. Rev. Anti. Infect. Ther., 6: 685-711.

34. Martinez-Martinez, L., Pascual, A. and Jacoby, G.A. (1998) Quinolone resistance from a transferable plasmid. Lancet, 351: 797-799.

35. Johnson, J.R., Kuskowski, M.A., Menard, M., Gajewski, A., Xercavins, M. and Garau, J. (2006) Similarity between human and chicken Escherichia coli isolates in relation to ciprofloxacin resistance status. J. Infect. Dis., 194: 71-78.

36. Agabou, A., Lezzar, N., Ouchenane, Z., Khemissi, S., Satta, D., Sotto, A., Lavigne, J.P. and Pantel, A. (2015) Clonal relationship between human and avian ciprofloxacin-resistant Escherichia coli isolates in North-Eastern Algeria. Eur. J. Clin. Microbiol. Infect. Dis., 35: 227-234. 